\title{
Rapid and Simple Determination of Plasma and Erythrocyte MDA Levels in Prostate Cancer Patients by a Validated HPLC Method
}

\author{
Zorica Arsova-Sarafinovska \\ Department for Drug Quality Control, Republic Institute for Health \\ Protection, Skopje, Macedonia
}

\author{
Ahmet Aydin, Ahmet Sayal, Ayşe Eken, and Onur Erdem \\ Department of Toxicology, Gulhane Military Medical Academy, Etlik, \\ Ankara, Turkey \\ Ayhan Savaşer \\ Department of Pharmaceutical Technology, Gulhane Military Medical \\ Academy, Etlik, Ankara, Turkey \\ Koray Erten and Yaşar Özgök \\ Department of Urology, Gulhane Military Medical Academy, Etlik, \\ Ankara, Turkey

\section{Aleksandar Dimovski} \\ Faculty of Pharmacy, Institute of Pharmaceutical Chemistry, Skopje, \\ Macedonia
}

\begin{abstract}
We undertook the present study to develop a validated HPLC method for the determination of malondialdehyde (MDA) levels and to use this method for determination of MDA levels in patients with prostate cancer and benign prostatic hyperplasia.

MDA levels were estimated in the erythrocyte and plasma sample of the 25 non-metastatic prostate cancer patients, 36 benign prostatic hyperplasia (BPH) patients
\end{abstract}

Address correspondence to Ahmet Aydin, Department of Pharmaceutical Toxicology, Gülhane Military Medical Academy, Ankara 06018, Turkey. Tel.: 0090 312 3046073; Fax: 0090312 3046091; E-mail: ahmetaydin30@ hotmail.com 
and 24 age- and sex-matched healthy subjects (controls) in HP Chromatographic systems consisting of a Model Agilent 1100 Series.

We report a very rapid and simple isocratic reversed-phase HPLC separation of MDA in normal human plasma and erythrocytes without previous purification of the MDA-TBA complex. All validation parameters were performed in our methods. Using this methods we have found elevated MDA in the plasma and erythrocyte of the prostate cancer group as compared to controls and BPH group.

We have improved and validated an analytical HPLC method for determination of MDA in plasma and erythrocyte, which is simple to perform and having high sensitivity, specificity and substantial improvement in column life. This method has been successfully applied to determination of MDA levels in prostate cancer patients and offers an oportunity to further characterize the role of oxidative injury in the pathogenesis of this disease specifically.

Keywords: Prostate cancer, Oxidative stress, Lipid peroxidation, HPLC

\section{INTRODUCTION}

Prostate cancer continues to be the most frequently diagnosed neoplasm, and the second leading cause of cancer-related mortality in men. ${ }^{[1-3]}$ Increasing evidence has indicated that oxidative stress is associated with aging and severe age-related degenerative diseases, including cancer. ${ }^{[4,5]}$ The most common group of indices used to assess oxidative stress is that of peroxidation products of lipids, usually polyunsaturated fatty acids, which are susceptible to attack by free radicals. ${ }^{[6]}$ One such byproduct of lipid peroxidation, malondialdehyde (MDA), is formed by $\beta$-scission of peroxidized polyunsaturated fatty acids and it is commonly measured by derivatization with 2-thiobarbituric acid (TBA) to yield a red compound. ${ }^{[7]}$ The method is simple and sensitive. Nevertheless, it has been found that some problems occur with this assay because aldehydes, other than MDA, can react with TBA and various other pigments may absorb at $532 \mathrm{~nm}$, giving an over-estimation of MDA concentrations. ${ }^{[8]}$

To overcome this lack of specificity for MDA, high-performance liquid chromatography (HPLC) of the MDA-TBA complex has been introduced. ${ }^{[9-22]}$ The separation of the complex from other interfering compounds by reversed-phase HPLC techniques has led to a reduction in observed MDA levels in various biological fluids. Ranges in control plasma are now reported as low as $1-2 \mu \mathrm{mol} \mathrm{L}{ }^{-1} \mathrm{MDA}^{[23]}$ which is more than a fivefold decrease from previous estimations where HPLC was not employed. ${ }^{[24]}$

However, to remove interfering substances and prevent column contamination, several methods require pretreatment of the TBA reaction mixture, such as neutralization, ${ }^{[9,14,22]}$ organic solvent extraction, ${ }^{[11,14,17]}$ solid phase extraction, ${ }^{[21]}$ and/or frequent column washing. ${ }^{[12,13,18,19]}$ For that reason, these procedures would not be acceptable in clinical laboratories where numerous assays are performed. Our objective was therefore to develop a 
method for MDA estimation with a high selectivity for MDA and being simple enough for routine determination.

To date, there are no data on HPLC analysis of MDA in biological fluids applied to samples from patients with prostate cancer. Therefore, we applied this method to evaluate the possible alteration of oxidant/antioxidant status in the circulation of patients with prostate cancer and benign prostatic hyperplasia.

\section{EXPERIMENTAL}

\section{HPLC Instrumentation and Conditions}

HPLC analyses were performed using an HP chromatographic system (Hewlett Packard, Avondale, USA) consisting of a Model Agilent 1100 series pump with a Model Agilent series G-13158 DAD detector and a Model Agilent 1100 series G-1329 ALS auto sampler. Data analyses were done using Agilent Technologies HPLC 1100 software. The separation was carried out at ambient temperature, on a reversed-phase Supelcosil LC-18 column $(150 \times 4.6 \mathrm{~mm}$ I.D.; particle size $5 \mu \mathrm{m})$. The chromatographic separation was performed using an isocratic mode. The elution was carried out at a flow rate of $0.75 \mathrm{ml} \mathrm{min}{ }^{-1}$. The injection volume was $50 \mu \mathrm{l}$. The column effluent was quantified at a wavelength of $532 \mathrm{~nm}$.

\section{Preparation of Solutions}

HPLC-grade methanol and acetonitrile were from Merck (Darmstadt, Germany). All other chemicals used in this study were of analytical grade and obtained from Sigma Chemical Co. (St. Louis, MO, USA) and Merck (Darmstadt, Germany). Double-distilled water was used to prepare mobile phase solutions.

The stock solution of 1,1,3,3 tetrametoxypropane, TMP, $\left(10 \mu \mathrm{mol} \mathrm{L}^{-1}\right)$ was prepared by dissolving $82.1 \mathrm{mg}$ of TMP in water-methanol $(50: 50, \mathrm{v} / \mathrm{v})$, diluted to $50 \mathrm{ml}$ and stored at $4{ }^{\circ} \mathrm{C}$. The working solutions were prepared by diluting the stock solution with water to concentrations of $0.5,1.0,1.5,2.0$, 2.5, 5.0, 10.0, 12.5, and $15.0 \mu \mathrm{mol} \mathrm{L}{ }^{-1}$. The stock solution was stable for 1 month at $4^{\circ} \mathrm{C}$, while working standards were freshly prepared daily.

A $0.042 \mathrm{~mol} \mathrm{~L}^{-1}$ 2-Thiobarbituric acid (TBA) solution was prepared by dissolving $0.6 \mathrm{~g}$ 2-TBA in approximately $80 \mathrm{ml}$ of water, and then heated while stirring on heat $\left(35-40^{\circ}\right)$ until dissolving. The solution was cooled to room temperature and filled with water to $100 \mathrm{ml}$ with water. The solution was stable for 7 days at $4^{\circ} \mathrm{C}$.

Potassium phosphate buffer solution $\left(0.02 \mathrm{~mol} \mathrm{~L}^{-1}, \mathrm{pH}\right.$ 6.4) was prepared by dissolving $2.72 \mathrm{~g}$ of anhydrous $\mathrm{KH}_{2} \mathrm{PO}_{4}$ in approximately $800 \mathrm{ml}$ of water and titrate to $\mathrm{pH} 6.4$ with $1 \mathrm{~mol} \mathrm{~L}^{-1} \mathrm{KOH}$ solution, monitoring constantly with a $\mathrm{pH}$ meter, and dilute to $1 \mathrm{~L}$ with water. 


\section{Mobile Phase}

In the present method, sufficient HPLC efficiency was obtained with a mobile phase consisted of acetonitrile-methanol- $0.02 \mathrm{~mol} \mathrm{~L}^{-1} \mathrm{KH}_{2} \mathrm{PO}_{4}, \mathrm{pH} 6.4$, 10:25:65 (v/v/v) at a flow rate of $0.75 \mathrm{ml} \mathrm{min}^{-1}$. The mobile phase was filtered through a $0.45 \mu \mathrm{m}$ filter and then degassed under vacuum.

\section{Study Subjects}

Twenty-five newly diagnosed men with prostate cancer (mean age: $67.5 \pm 8.8$ yr; range: $49-80 \mathrm{yr}$ ) and thirty-six men with benign prostatic hyperplasia (mean age: $64.3 \pm 7.9 \mathrm{yr}$; range: $46-79 \mathrm{yr}$ ), who had not undergone any previous treatment for their tumors, were enrolled in this study. All patients were recruited from the outpatient clinic of Urology Department of Gulhane Military Medical Academy. Twenty-four age-matched male subjects (mean age: $65.0 \pm 6.0 \mathrm{yr}$; range: $52-74 \mathrm{yr}$ ) served as controls. Specific exclusion criteria considered for the present study were: the presence of liver dysfunction, diabetes mellitus, heart failure or renal failure; smoking and oral antioxidant supplementation at the moment of the enrollment. None of the subjects had drinking habit and none of them had consumed any alcohol, starting at least 48 hours prior to blood collection. Informed consent was obtained from all participants of the study before the blood collection. All prostate cancer patients were classified as localized or locally advanced disease, with no evidence that the cancer has spread to lymph nodes, bones, or internal organs. 6 patients were classified as stage I, 15 patients as stage II and 4 patients as stage III.

The diagnosis of BPH or prostate cancer was based on the histopathological examination of their biopsy specimens. The prostate cancer was staged according to the TNM system of the American Joint Committee on Cancer (AJCC) by DRE, PSA level at diagnosis, transrectal ultrasound, and biopsy Gleason sum. Other diagnostic methods included ultrasound-guided biopsy, pelvic computerized tomography, magnetic resonance imaging and radionuclide bone scanning.

\section{Sample Collection and Analysis}

Blood samples were drawn from the antecubital vein following an overnight fast, by venipuncture into tubes containing EDTA. They were centrifuged for $10 \mathrm{~min}$. at $4000 \mathrm{~g}$ and $4{ }^{\circ} \mathrm{C}$. After separation of plasma, the buffy coat was removed and the packed cells washed three times with two volumes of isotonic saline. Then, a known volume of erythrocytes was lysed with cold distilled water (1:4), stored in a refrigerator at $4^{\circ} \mathrm{C}$ for $15 \mathrm{~min}$. and the cell debris were removed by centrifugation $\left(2000 \mathrm{~g}\right.$ at $4^{\circ} \mathrm{C}$ for $10 \mathrm{~min}$.). Plasma samples and erythrocyte lysates were stored at $-70^{\circ} \mathrm{C}$ until assayed. 
$100 \mu \mathrm{l}$ of $5 \%$ TCA (aqueous) was added to a sample of $25 \mu \mathrm{l}$ plasma, erythrocyte lysate or standard, vortex-mixed and centrifuged at $4000 \mathrm{~g}$ for $10 \mathrm{~min}$. An aliquot of $75 \mu \mathrm{l}$ supernatant samples and $50 \mu \mathrm{l}$ of $0.042 \mathrm{~mol} \mathrm{~L}^{-1}$ TBA (aqueous) were transferred to a clean tube and vortexmixed. The mixture was placed in a heating bath at $95^{\circ} \mathrm{C}$ for $55 \mathrm{~min}$, and then cooled rapidly under running water. After final centrifuge at $4000 \mathrm{~g}$ for $10 \mathrm{~min}$, an aliquot of $50 \mu \mathrm{l}$ was directly injected into the HPLC system.

To maintain optimal separation performance and avoid buffer precipitation, the column was regenerated with $15 \mathrm{ml}$ of water followed by $15 \mathrm{ml}$ of methanol at a flow rate of $0.5 \mathrm{ml} / \mathrm{min}$ after each day of analysis.

\section{Statistical Analysis}

All results were presented as mean \pm standard deviation (SD). Comparisons among the different groups were carried out by ANOVA tests followed by Tuckey-Kramer's multiple comparisons test a posteriori. The values were considered statistically significant if the $\mathrm{p}$ value was less than 0.05 .

\section{RESULTS AND DISCUSSION}

Several HPLC methods have been developed for the determination of MDA in human plasma. However, these techniques generally require: a long execution time, and pre-purification of the MDA-TBA complex or elimination of interfering substances. We report a very rapid and simple isocratic reversed-phase HPLC separation of MDA in normal human plasma and erythrocytes without previous purification of the MDA-TBA complex.

Volpi and Tarugi (1999) reported a highly sensitive HPLC technique for measuring MDA in normal human plasma. This method separates the MDATBA complex on reversed-phase HPLC using 65\% $0.05 \mathrm{~mol} \mathrm{~L}^{-1} \mathrm{NaH}_{2} \mathrm{PO}_{4}$, $\mathrm{pH} 7.0,35 \%$ methanol. We first applied the above method exactly at stated $\mathrm{pH}$ levels for detection of MDA-TBA complexes and we did not get satisfactory results. We have tested many different mobile phases and the one consisted of $65 \% 0.02 \mathrm{~mol} \mathrm{~L}^{-1}$ potassium phosphate buffer, $\mathrm{pH} 6.4,10 \%$ acetonitrile, and $25 \%$ methanol was found optimal by us for isocratic determination of the MDA-TBA complex in human plasma and erythrocytes. A buffer reagent had to be used, otherwise tailing became too prominent. The effect of the $\mathrm{pH}$ and concentration of the potassium phosphate buffer were evaluated. The maximum formation of TBA-MDA adducts and high recovery was obtained at $\mathrm{pH} 6.4$ and concentration of the potassium phosphate buffer of $0.02 \mathrm{~mol} \mathrm{~L}^{-1}$. In the present method, the reaction mixture was therefore injected into HPLC using the auto sampler without any pretreatment except for centrifugation.

MDA was identified on the basis of retention time by comparison with the MDA standard. Furthermore, the MDA adduct was identified by adding 
standard to sample prior to derivatisation, which resulted in an increased sample peak area that was proportional to the added amount.

The average retention time of the MDA-TBA adduct was approximately

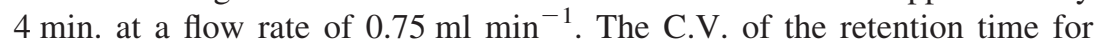
within-assay $(\mathrm{n}=20)$ and between-assay $(\mathrm{n}=10)$ were 1.1 and $2.9 \%$, respectively. The TBA-MDA adduct was determined in a short time as a sharp single peak. About 8 min was required for each analysis. No interference from other TBA reactive substance was observed.

\section{Calibration and Detection Limit}

The linearity was assessed by analysis of TMP standards ranging from 0.5 to $12.5 \mu \mathrm{mol} \mathrm{L}{ }^{-1}$ TMP. A typical calibration plot is shown in Figure 1, with a regression line corresponding $\mathrm{y}=707.64 \times+1.9853$, and $\mathrm{r}^{2}=0.9994$. Furthermore, the linearity of the proposed method has been proved over a wide concentration range $\left(0.5-12.5 \mu \mathrm{mol} \mathrm{L}{ }^{-1} \mathrm{TMP}\right)$ that allows the determination of lipid peroxidation in plasma and erythrocyte samples on the same day with the same standard curve. In the other published methods ${ }^{[11]}$ separate calibration curves should be constructed for plasma and erythrocytes/tissue homogenates respectively.

\section{Detection Limit}

The limit of detection (LOD) was $0.045 \mu \mathrm{mol} \mathrm{L}^{-1}$ (corresponding to $2.25 \mathrm{pmol} \mathrm{MDA} / 50 \mu \mathrm{l}$ injected) and it was calculated from $3.3 \mathrm{SD}_{\mathrm{bl}} / \mathrm{S}$, where $\mathrm{SD}_{\mathrm{bl}}$ is the standard deviation of 10 separate blank measurements and $\mathrm{s}$ is the slope of the calibration curve ${ }^{[16]}$ The limit of quantification $\left(\mathrm{LOQ}=10 \mathrm{SDbl} / \mathrm{S}\right.$ ) was $0.135 \mu \mathrm{mol} \mathrm{L}^{-1}$ (corresponding to $6.75 \mathrm{pmol}$ $\mathrm{MDA} / 50 \mu \mathrm{l}$ injected), i.e., well below actual plasma concentration.

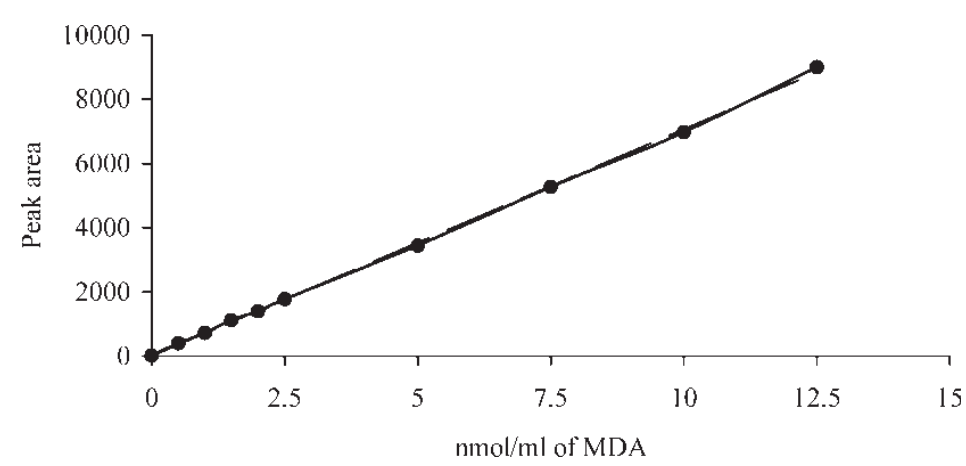

Figure 1. A typical TMP calibration line, with regression line $\mathrm{y}=707.64 \times+1.9853$, and $\mathrm{r}^{2}=0.9994$. 
Plas ma MDA levels

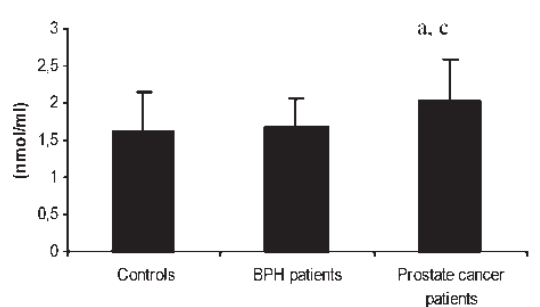

Erythrocyte MDA levels

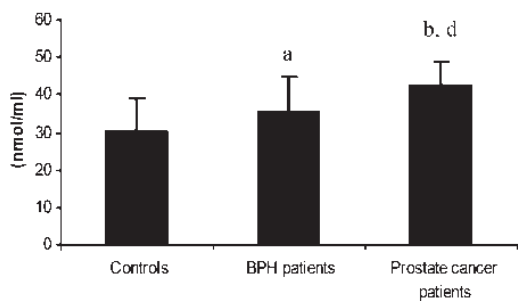

Figure 2. Erythrocyte and plasma MDA levels in controls, BPH and cancer patients Values are indicated by mean \pm SD. BPH: Benign prostatic hyperplasia; MDA: Malondialdehyde. ${ }^{\mathrm{a}}$ - as compared with controls, $\mathrm{p}<0.05 ;{ }^{\mathrm{b}}$ - as compared with controls, $\mathrm{p}<0.001 ;^{\mathrm{c}}$ - as compared with benign prostatic hyperplasia group, $\mathrm{p}<0.05 ;^{\mathrm{d}}$ - as compared with benign prostatic hyperplasia group, $\mathrm{p}<0.01$.

\section{Precision}

Intra-assay precision was evaluated by 5 repeated, separated measurements on the same day, of the pooled samples of plasma and erythrocytes obtained from the control subjects, and was found to be $4.1 \%$ for plasma measurement and $2.2 \%$ for erythrocytes, respectively. Either 5 repeated, separated measurements on the same day of 0.5 and $5 \mu \mathrm{mol} \mathrm{L}{ }^{-1}$ TMP standard solutions have been done, and the intra-assay precision was found to be $2.7 \%$ and $1.4 \%$, respectively (Figure 2 ).

Inter-assay precision was evaluated by five different measurement of the pooled sample of plasma and erythrocytes on the five consecutive days and was found to be $9.1 \%$ and $8.8 \%$ for the samples, respectively. The inter-assay precision for the 0.5 and $5 \mu \mathrm{MTMP}$ standard solutions was $7.9 \%$ and $5.4 \%$, respectively. These results indicate sufficient reproducibility for clinical application.

\section{Recovery}

Recovery of the TBA-MDA adduct was evaluated by addition of known amounts of standard to the pooled plasma to give concentrations of $0.5,1.5$, and $2.5 \mu \mathrm{mol} \mathrm{L}{ }^{-1}$ TMP. The average recovery for the tested amounts was $95.6 \% \pm 2.5 \% \quad(\mathrm{n}=15)$. Also the known amounts of standard stock solution were added to the pooled erythrocyte lysate to give concentration of 5 , and $10 \mu \mathrm{mol} \mathrm{L}{ }^{-1}$ TMP. The average recovery for the tested amounts was $97.4 \% \pm 1.3 \%(\mathrm{n}=10)$.

\section{Applications}

MDA is a highly reactive aldehyde, capable of modifying both DNA and proteins, resulting in mutagenic, genotoxic and cytotoxic events. Some of 
the identified DNA lesions are known to be pre-mutagenic and may play a role in carcinogenesis. A possible link between these biochemical alterations and a risk of developing prostate cancer was suggested. ${ }^{[25]}$ Therefore, high levels of MDA could explain DNA base modifications found by Olinski et al. (25) in prostate cancer tissues.

Using this method, we have found elevated lipid peroxidation in the plasma and erythrocytes of the prostate cancer group as compared to controls and BPH group. To date, studies that examine the relationship between lipid peroxidation and cancer have given contradictory results. It is generally believed that there is an inverse relationship between the concentration of lipid peroxides and the degree of malignancy deviation of the tumor cells i.e. the higher the rate of lipid peroxidation in the cells the lower the rate of cell division. ${ }^{[26]}$ Our findings were in agreement with the reports of Biri et al.; ${ }^{[27]}$ Yilmaz et al., ${ }^{[28]}$ who have reported increased TBARS concentrations suggesting oxidative stress and accelerate peroxidative reactions in the cancerous prostate tissues, even though antioxidant defense mechanisms were activated. However, DogruAbbasoglu et al. ${ }^{[29]}$ have found no significant change in lipid peroxidation or antioxidant system parameters in the plasma of patients with BPH and prostate cancer.

Furthermore, we have found about 20-fold higher MDA concentration in erythrocyte samples than in plasma. It could be explained by the fact that erythrocytes are particularly vulnerable to oxidative damage due to: a) continuous exposure to high oxygen tension, b) the large contents of polyunsaturated fatty acids, major target for peroxidation, and c) the presence of large amounts of iron, a potent catalyst of oxygen free radical production. ${ }^{[30,31]}$

We hypothesize that an altered prooxidant-antioxidant balance may lead to an increase oxidative damage and consequently may play an important role in the prostate carcinogenesis. The evaluation of oxidative stress involvement in the etiology of the prostate cancer could contribute in the better understanding of cause and development of this disease.

The further researches should be planned in order to find whether the oxidative stress related parameters could be used as differential diagnostic and prognostic tools in prostate cancer and BPH. Moreover, they could help to improve the sensitivity and specificity of the existing detection techniques. The improved risk stratification and outcome prediction would enhance the physician's ability to counsel patients about treatment option and their associated risk and benefits.

In conclusion, we have improved and validated an analytical HPLC method for determination of MDA in plasma and erythrocytes, which is simple to perform and having high sensitivity, specificity and substantial improvement in column life. The limit of quantification $\left(0.135 \mu \mathrm{mol} \mathrm{L}^{-1}\right.$ or $6.75 \mathrm{pmol} \mathrm{MDA} / 50 \mu \mathrm{l}$ injected on the column) is adequate for routine quantification of MDA in plasma. It could therefore be used for routine clinical analysis. The method has been successfully applied to the study of the lipid 
peroxidation levels in the circulation of prostate cancer patients and offers an oportunity to further characterize the role of oxidative injury in the pathogenesis of this disease.

\section{REFERENCES}

1. Jemal, A.; Tiwari, R.C.; Murray, T.; et al. Cancer statistics, 2004. CA Cancer J. Clin. 2004, 54, 8-29.

2. Moul, J.W.; Anderson, J.; Penson, D.F.; Klotz, L.H.; Soloway, M.S.; Schulman, C.C. Early prostate cancer: Prevention, treatment modalities, and quality of life issues. Eur. Urol. 2003, 44, 283-93.

3. Nelson, W.G.; DeMarzo, A.M.; Isaacs, W.B. Prostate cancer. NEJM Mechanisms of Disease 2003, 349, 366-81.

4. Ripple, M.O.; Henry, W.F.; Rago, P.R.; Wilding, G. Prooxidant-antioxidant shift induced by androgen treatment of human prostate carcinoma cells. J. Natl. Cancer Inst. 1997, 89, 40-8.

5. Oberley, T.D.; Oberley, L.W. Oxygen radicals and cancer. In Free Radicals in Aging; Yu, B.P. (Ed.); CRC Press: Boca Raton, FL, 1993, 247-6.

6. Dotan, Y.; Lichtenberg, D.; Pinchuk, I. Lipid peroxidation cannot be used as a universal criterion of oxidative stress. Progress in Lipid Research 2004, 1-28.

7. Draper, H.H.; Hadley, M. Malondialdehyde determination as index of lipid peroxidation. Methods Enzymol 1990, 186, 421-31.

8. Badcock, N.R.; Zoanetti, G.D.; Martin, E.S. Nonchromatographic assay for malondialdehyde-thiobarbituric acid adduct with HPLC equivalence. Clin. Chem. 1997, $43,1655-57$.

9. Nielsen, F.; Mikkelsen, B.B.; Nielsen, J.B.; Andersen, H.R.; Grandjean, P. Plasma malondialdehyde as biomarker for oxidative stress: reference interval and effects of life-style factors. Clin. Chem. 1997, 43 (7), 1209-1214.

10. Fukunaga, K.; Yoshida, M.; Nakazono, N. A simple, rapid, highly sensitive and reproducible quantification method for plasma malondialdehyde by highperformance liquid chromatography. Biomed. Chromatograph 1998, 12, 300-303.

11. Lykkesfeldt, J. Determination of malondialdehyde as dithiobarbituric acid adduct in biological samples by HPLC with fluorescence detection: Comparision with Ultraviolet-Visible Spectrophotometry. Clin. Chem. 2001, 47 (9), 1725-1727.

12. Volpi, N.; Tarugi, P. Improvement in the high-performance liquid chromatography malondialdehyde level determination in normal human plasma. J. Chromat. B, 1998, 713, 433-437.

13. Templar, J.; Kon, S.P.; Milligan, T.P.; Newman, D.J.; Raftery, M. Increased plasma malondialdehyde levels in glomerular disease as determined by a fully validated HPLC method. Nephrol. Dial. Transplant 1999, 14, 946-951.

14. Pilz, J.; Meineke, I.; Gleiter, C.H. Measurement of free and bound malondialdehyde in plasma by high-performance liquid chromatography as the 2,4dinitrophenylhydrazine derivative. J. Chromat. B, 2000, 742, 315-325.

15. Claeson, K.; Thorsen, G.; Karlberg, B. Methyl malondialdehyde as an internal standard for the determination of malondialdehyde. J. Chromat. B, 2001, 751, $315-323$.

16. Larstad, M.; Ljungkvist, G.; Olin, A.C.; Toren, K. Determination of malondialdehyde in breath condensate by high-performance liquid chromatography with fluorescence detection. J. Chromat. B 2001, 766, 107-114. 
17. Agarwal, R.; Chase, S.D. Rapid fluorimetric-liquid chromatographic determination of malondialdehyde in biological samples. J. Chromat. B 2002, 775, $121-126$

18. Karatas, F.; Karatepe, M.; Baysar, A. Determination of free malondialdehyde in human serum by high-performance liquid chromatography. Anal. Biochem. 2002, 311, 76-79.

19. Li, K.; Shang, X.; Chen, Y. High-performance liquid chromatographic detection of lipid peroxidation in human seminal plasma and its application to male infertility. Clin. Chem. Acta. 2004, 346, 199-203.

20. Lepage, G.; Munoz, G.; Champagne, J.; Roy, C.C. Preparative steps necessary for the accurate measurement of malondialdehyde by high-performance liquid chromatography. Anal. Biochem. 1991, 197, 277-283.

21. Draper, H.H.; Squires, E.J.; Mahmoodi, H.; Wu, J.; Agarwal, S.; Hadley, M. A comparative evaluation of thiobarbituric acid methods for the determination of malondialdehyde in biological materials. Free Radic. Biol. Med. 1993, 15 (4), 353-63.

22. Londero, D.; Lo, G.P. Automated high-performance liquid chromatographic separation with spectrofluorometric detection of a malondialdehyde-thiobarbituric acid adduct in plasma. J. Chromatogr. A 1996, 729, 207-210.

23. Diaz-Velez, C.R.; Garcia-Castineiras, S.; Mendoza-ramos, E.; et al. Increased malondialdehyde in periferal blood of patients with congestive heart failure. Am Heart J. 1996, 131, 146-152.

24. Dasgupta, A.; Hussain, S.; Ahmad, S. Increased lipid peroxidation in patients on maintenance haemodialysis. Nephron. 1992, 60, 56-59.

25. Olinski, R.; Zastawny, T.H.; Foksinski, M.; Barecki, A.; Dizdaroglu, M. DNA base modifications and antioxidant enzyme activities in human benign prostate hyperplasia. Free. Radic. Biol. Med. 1995, 18, 807-813.

26. Das, U.N.; A radical approach to cancer. Med. Sci. Monit. 2002, 8, RA79-92.

27. Biri, H.; Ozturk, H.S.; Kacmaz, M.; Karaca, K.; Tokucoglu, H.; Durak, I. Activities of DNA turnover and free radical metabolizing enzymes in cancerous human prostate tissue. Cancer Invest. 1999, 17, 314-9.

28. Yilmaz, M.I.; Saglam, K.; Sonmez, A.; et al. Antioxidant system activation in prostate cancer. Biol. Trace. Elem. Res. 2004, 98, 13-9.

29. Dogru-Abassoglu, S.; Aykac-Toker, G.; Kocak, T.; Unluer, E.; Uysal, M. Antioxidant enzyme activities and lipid peroxides in the plasma of patients with benign prostatic hyperplasia or prostate cancer are not predictive. J. Cancer Res. Clin. Oncol. 1999, 125, 402-4.

30. Kumaraguruparan, R.; Subapriya, R.; Kabalimoorthy, J.; Nagini, S. Antioxidant profile in the circulation of patients with fibroadenoma and adenocarcinoma of the breast. Clin. Biochem. 2002, 35, 275-9.

31. Ripple, M.; Mulcahy, R.T.; Wilding, G. Characteristics of the glutathione/glutathione-S-transferase detoxification system in melphalan resistant human prostate cells. J. Urol. 1993, 150, 209-14.

Received February 24, 2007

Accepted April 19, 2007

Manuscript 6071 